\title{
La alfarera codiciosa \\ Políticas de reciprocidad y valores de cambios en los Andes del Sur ${ }^{1}$
}

\author{
Pedro Mege R.
}

\section{RESUMEN}

En el poblado aimara de Machuca, en el marco de la celebración festiva de su santo patrono, Santiago, se realiza una feria organizada y dirigida por las mujeres, en la cual se desarrolla un nutrido intercambio de bienes en celebración a santa Ana. Se intercambian textos y fragmentos de cerámica por alimentos y bebidas, los que son consumidos como actos de reciprocidad. La realización de esta feria supone la ejecución de una compleja performance en la que participa todo el poblado y los invitados para la ocasión. Se lleva a cabo en el espacio sagrado de la iglesia, lo que implica que sus participantes deben seguir un estricto protocolo de acciones controladas por los hombres bajo la supervisión de las mujeres de Machuca.

1 Investigación realizada en el marco de los proyectos: Fondecyt-Universidad Católica de Chile N. 1141032 y Fondap-Universidad Católica de Chile N. ${ }^{\circ}$ 1511006. 
Palabras clave: fiesta, feria, reciprocidad, ritual, performance, intercambio, valor de cambio y comensalismo

\begin{abstract}
In the Aymara town of Machuca, in the context of the celebration of the Patron Saint Santiago, a market is organized and directed by women. In this instance, a rich exchange of goods in celebration to Santa Ana takes place. Texts and fragments of ceramic are interchanged for food and beverages in an act of reciprocity. The realization of this fair supposes the execution of a complex performance in which the whole town and those invited for the occasion participate. It takes place in the sacred space of the church which implies that the participants must obey a strict protocol of actions controlled by men under the supervision of women from Machuca.
\end{abstract}

KEYwORDs: party, fair, reciprocity, ritual, performance, exchange, exchange value and commensality

En el poblado de Machuca, en las alturas de los Andes, ${ }^{2}$ dentro del contexto de la celebración sacra de la fiesta de san Santiago Apóstol, ${ }^{3}$ en su último día ritual y en el mediodía de la jornada, y para el día de santa Ana del 26 de julio, encontramos un giro hacia la profanidad. Este giro vuelca la celebración del santo en el de la santa, y en una recreación performativa y profana del sistema de reciprocidades e intercambios del pueblo. Tiene como particularidad abarcar a la totalidad de la comunidad ritual, desde los niños y los agentes rituales, hasta visitas e intrusos. Comunidad que entenderemos y definiremos siguiendo a Victor Turner como communitas, la

2 Región de Antofagasta, norte de Chile.

3 Para las comunidades indígenas del Altiplano chileno, la etnocategoría que utilizan para referirse al Apóstol Santiago es San Santiago; para ellos, Santiago no supone el afijo San como significado de santo, no se entiende la inclusión de la apócope de santo. Somos fieles a la denominación de los propios aimaras. 
que se produce «en el fenómeno liminal», en esos ritos «que se producen en y fuera del tiempo» (Turner 1982: 96). Comunidad ${ }^{4}$ aimara con una profunda historia de reciprocidades e intercambios enraizadas en la estructura organizativa del ayllu (Kessel 1996: 47-67).

En esta ritualidad se trata de ejecutar, de poner en escena una explicitación de las redes de intercambio de favores económicos y comerciales a través de un rito-performance de gran sofisticación, donde el juego de valores y prestaciones queda representado en cosas y las relaciones de intercambios sociales, en performances. Es así como el sistema ritual de la celebración al santo Santiago abandona su sacralidad y redefine el contexto de manera integral en una feria del intercambio. Cada oficiante y participante asume unos papeles performativos nuevos; cada invitado también. Todo el espacio ritual sacro de la fiesta hasta ese momento se redibuja, los movimientos se alteran, las palabras son rehechas en base a la instalación de una simbología ritual distinta ${ }^{5}$ del intercambio alejada de la ritualidad santiaguina y ahora bajo la tutela de santa Ana.

Como dijimos, durante varios días se ha celebrado al patrono de Machuca, san Santiago, siguiendo un estricto protocolo ritual; pero en el día final de su celebración se trastoca el sentido de la fiesta cerca del mediodía y se comienza con la reorganización y con el cambio para pasar de una fiesta religiosa hacia una performativa profana de los espacios, los tiempos y las personas en celebración de santa Ana, protectora de los comerciantes.

4 Communitas como «modelo» de interrelacional, el cual «emerges recogniziably in the liminal period, is of society as an unstructured or rudimentarily structured and relatively undiferentiated comitatus, community, or even communion of equal individuals who submits together to the general authority of the ritual elders» (Turner 1982: 96). Entendiendo que el rito tiene su «estructura», que es desarticuladora de la estructura cotidiana de tiempos, espacios y jerarquías.

5 Victor Turner (2008: 299) comprende los «símbolos rituales» como las unidades mínimas componentes del ritual, integrados por «objetos, actividades, relaciones interpersonales, gestos, eventos y unidades espaciales en una situación ritual». 


\section{El ritual sagrado redefinido como feria profana: Cambio Y SIGNIFICADO}

The performance has become: index and symbol, multiple truth and lies, arena of struggle. [...] Performance is amoral, as useful to tyrants as to those practice guerrilla theatre. This amorality comes from performance's subject, transformation: the startling ability of human beings to create themselves, to change, to become - for worse or better- what ordinarily are not (Schechner 1995: 1). ${ }^{6}$

Entenderemos el rito a partir de una amplia gama de autores que pensamos que siguen una línea argumentativa y que se complementan mutuamente en los aspectos que tocan en relación a la comprensión del rito: en su forma estructural elemental y sus secuencias ceremoniales de liminalidades, desde Arnold van Gennep (2008); la clásica distinción de regulación y repetición de acciones, a partir de Jean Cazeneuve (1972); de un proceso anti-estructural, desde Victor Turner (1982), y como actividad de subversión de los espacios y tiempos cotidianos, con Jean Duvignaud (1979). Pero este ritual posee muy particularmente un carácter performativo. No es como en un ritual convencional, donde los participantes asumen conductas pertinentes al ritual — podríamos decir que las encarnan-, aquí se «actúa» de manera particular, en el sentido que se representan, teatralizan conscientemente unas formas de interacción y unos roles particulares en una dramaturgia explícita (Schechner 2000; Turner 1988; Taylor y Fuentes 2011).

No se trata aquí de una «verdadera» feria, sino de la instalación de una representación de una feria, cuya finalidad no es el comercio

6 «La demostración ha empezado: indicio y símbolo, verdad y mentira se multiplican, es la arena del combate [...]. La representación es amoral, como suele ser para los tiranos y para los que participan en un escenario de guerrilla. Esta amoralidad procede del objeto de la demostración, del cambio: la incesante habilidad de los seres humanos de crearse a sí mismos, de cambiar y de llegar a ser — para bien o para mal— lo que ordinariamente no son» [La traducción es nuestra]. 
y la ganancia, sino develar la reciprocidad en un círculo comunitario por medio de la simulación simbólica de las relaciones de intercambio. Se trata de demostrar que el capital queda subordinado a las relaciones entre las personas.

«Por sus performances los reconoceréis [...] las culturas se expresan más completamente en sus performances rituales y teatrales, y gracias a ello adquieren conciencia de sí mismas», nos recuerda Schechner de lo que dijo Victor Turner en un comité, por los años ochenta (Schechner 2000: 16 [las cursivas son nuestras]). Las personas de Machuca explicitan en su performance de la feria el sentido del intercambio comensalístico, la visión de los diferentes personajes intervinientes —alfareras celosas, pacos (chilenismo referido a los carabineros, la policía chilena), fabriquero, la comunidad ritual y visitas - y en donde cada participante cumple unas actuaciones que son la proyección y explicitación de la cotidianidad de las relaciones de los agentes de la comunidad.

\section{Tránsito de los significantes categoriales: instalación de los} signos de la feria. Como ya dijimos, el Primer Tránsito simbólico se vincula al calendario ritual de Machuca y de los Andes en general: en la fiesta de san Santiago se abre el espacio-tiempo de la feria ${ }^{7}$ de santa Ana.

El Segundo Tránsito supone que la autoridad se desplaza del líder oficiante cúltico de la fiesta, el alférez del santo, al líder controlador y vigilante de la feria, el fabriquero de Machuca, autoridad «aimara con prestigio y autoridad moral [...] encargado de los bienes de la iglesia y mantención del templo» (Kessel 1996: 53), que, aunque estando asociado a lo religioso, se vincula a su aspecto más profano, su conservación material, diríamos, su valor profano. Hay un segundo desplazamiento de autoridad; de la relativa simetría

7 Utilizaremos feria con minúscula para referirnos en un sentido genérico y con mayúscula para referirnos específicamente a la feria de Machuca. 
entre hombres y mujeres en la fiesta de san Santiago, las mujeres adquieren una mayor jerarquía que la masculina, ellas serán las proveedoras de los valores de intercambio, ya que «el dar es signo de superioridad, de ser más, de estar más alto» (Mauss 1971: 255).

El Tercer Tránsito se ubica en el plano de la ejecución ritual. Como primera acción del nuevo escenario, la feria, se clausuran dos espacios que antes eran accesibles parcialmente: la iglesia, que se cierra con candado - no su campanario que tendrá una función en el transcurso de la celebración de la Feria - y el espacio ritualperformativo, conformado por el patio de la iglesia. Si en la Fiesta de Santiago la clausura era social — no se permitía el acceso a cualquiera-, ahora la clausura es física, se cierran las puertas de la iglesia y el patio.

Itinerario del ritual redefinido. Los oficiantes dirigidos por el fabriquero expulsan del campo ceremonial a toda persona que se encuentre en él, visitas e intrusos eventuales, recinto que está claramente delimitado por el espacio sacro ritual de la iglesia y su patio, con su pedestal calvario con su cruz al centro del campo.

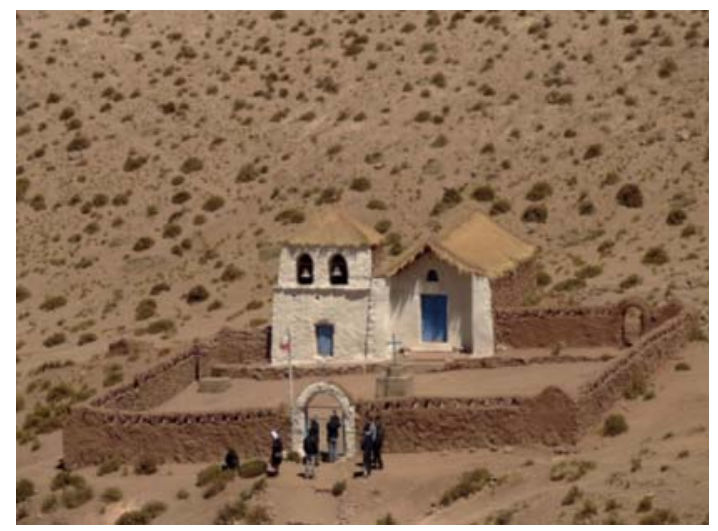

Fotografía 1: Iglesia de Machuca. Fuente: www.expenews.com 
Definiremos al campo ritual-performativo como arena, «que es el emplazamiento concreto en el cual el paradigma se transforma en metáfora y símbolo, en referencia a la movilización del poder político que provoca una fuerte lucha entre la instalación de influencias paradigmáticas divergentes» (Turner 1975: 17). ${ }^{8}$ Como se sabe, Turner sigue en su concepción de metáfora a Max Black en su obra ya clásica, y la define básicamente y para nuestros propósitos como «our means of effecting instantaneuos fusion of two separated realms of experience into one illuminaiting, iconic, encapsulting image» (Black 1962: 4). ${ }^{9}$ Para nuestros fines, la metáfora de la performance articulará dos formas de intercambio, unirá los dominios del comercio y la reciprocidad: el dominio de lo escrito en un valor enajenado de cambio, papel escrito como billete, y relaciones comensalísticas ${ }^{10}$ de intercambio personal, sujetos de la escritura (carnet) y sujetos de los objetos (fragmentos de cerámica) que intercambian cara a cara. Evidentemente, la metáfora «icónica»y de «imágenes encapsuladas» es la feria.

La entrada, custodiada por una reja de fierro y candado, en donde se ubica la asta con la bandera chilena, fuera del espacio ritual, pero señalando el acceso, es lo chileno. El Estado de Chile está en los márgenes, pero en la entrada, de ahí que en este se exija el carnet, símbolo de la personificación del sujeto por parte del Estado chileno en su gesto de ideología burocratizante. Es un espacio

8 Entendiendo por paradigma «un set de «reglas» generador de específicas secuencias de acción social y de actuar sobre otras secuencias que deben ser excluidas» (Turner 1975: 17).

9 «Nuestra comprensión de la fusión efectivamente instantánea de dos realidades separadas de nuestra experiencia, en una imagen englobante, luminosa y reveladora» [La traducción es nuestra].

10 Entenderemos comensalístico como lo entienden los ecólogos culturales: «relación [...] que surge entre criaturas similares, miembros de una especie dada, o, más bien, individuos que hacen demandas similares al medio» (Hawley 1975: 53). Esta es la relación de comensalismo que, literalmente interpretada, quiere decir, «comer de la misma mesa» (Hawley 1975: 53). 
amurallado, lo que le da una clara delimitación perimetral y permite excluir inicialmente a los que no ofician y dirigen el rito-performance.

Fuera del espacio de la feria, al otro lado de la muralla y la reja de hierro con candado, se ubican los guardianes del rito-performance, los pacos, los carabineros: son miembros de la comunidad de Machuca que asumen el rol de vigilantes y sancionadores del orden de los protocolos rituales. Nadie puede entrar al campo ritual, solo pacos, encargados de ejecutar el rito. Los pacos, denominación popular que recae sobre la policía, el cuerpo de Carabineros de Chile, tiene una clara connotación de desprecio y alude a su condición de sancionadores intransigentes y algo arbitrarios. Estos se visten con casco de seguridad mineros y chalecos refractantes, expresando una inconfundible y reconocible representación de autoridad formal exógena y represora. Llevan, además, palos, lumas, ${ }^{11}$ como distintivos inconfundibles del uso legítimo de la fuerza y rol sancionador; otro elemento característico es el lenguaje que utilizan, que se particulariza por ser obviamente autoritario y utilizar la jerga terminológica de los policías, con expresiones tales como «proceda», «requisar», «llevar detenido», «identifíquese», etcétera.

Vigilarán la dinámica de las relaciones y sancionarán, a partir de un código estricto, el cumplimiento de los protocolos rituales y acciones performativas. Además, son los encargados de redefinir los movimientos en el espacio de la feria, al trazar los senderos con tiza por donde circularán los participantes del ritual-performance y al demarcar los puestos de consumo de alimentos y bebidas de las mujeres ofertantes de dones. Los pacos ordenan la arena de la feria a partir de un principio de exclusión-inclusión de los espacios: fuera de las murallas y al otro lado de las rejas, al espacio de lo doméstico y cotidiano; dentro de estos, el espacio ritual-performativo, dónde se puede pisar, en los senderos de tiza, y dónde no se puede pisar, fuera de ellos.

11 Se llama luma a los bastones de la policía por ser originalmente de madera del árbol de la luma, de ahí su nombre. 
Mientras los pacos vigilan el acceso, al interior del espacio ritual se desarrolla una actividad frenética, se está organizando el circuito de los intercambios y de la reciprocidad. ¿Qué se va a traspasar entre los participantes del ritual? Valor de cambio por bienes, diremos que monedas por comida y bebidas. El intercambio se producirá por medio de una economía política de las mujeres alfareras, ellas serán las proveedoras del circulante y de la comida, ya que es «la alfarera la que llevaba sus productos al mercado, a la feria» (Lévi-Strauss 2008: 19). Los hombres, es decir, los pacos, solo supervisarán, vigilarán y castigarán; las mujeres intercambiarán valores por medio de un circuito complejo de reciprocidades.

Parroquianos, visitantes y etnólogos: el carácter profano del ritual lo hace más libre en relación a sus participantes y solo hay que cumplir con las regulaciones performativas. A las visitas invitadas y a las esporádicas se las incluirán, solo es cuestión de que se inscriban en el juego de las reciprocidades. Para las participaciones en contextos sagrados, la comunidad ritual es mucho más estricta en su selección de participantes. En la fiesta de Santiago, el nivel clausura que impone lo sagrado en comparación con la profana feria de santa Ana es mucho mayor, dado sus diferentes procedimientos de intercambio entre, por un lado, la comunidad y los dioses y, por otro, las mujeres y la comunidad. La performática ritual sagrada está encriptada y es, por definición, excluyente; en el espacio del intercambio profano, todos entienden lo que es un mercadeo, aunque no todos descubran el sentido de la reciprocidad de la feria del villorrio de Machuca.

\section{EL RITO-PERFORMANCE FERIAL EN CINCO ACTOS}

La descripción del rito tiene como componentes necesarios a las personas, los lugares y los tiempos. ${ }^{12}$ Incluye personas con una

12 El equipo de campo, al que agradezco especialmente su ayuda mnemotécnica y su gran capacidad de rapport, lo integran Bárbara Ossa y Jaime Álvarez, como 
asignación performativa específica, llamados ejecutantes: alfareras codiciosas, ayudantas de las alfareras, fabriquero y pacos; y personas sin una asignación performativa específica, o participantes: habitantes de Machuca (incluyendo los antiguos), visitantes invitados, intrusos, principalmente turistas, y, en este caso, etnólogos. La escena se establece en el momento en que todos están reunidos en el espacio ritual-performativo, al finalizar la mañana en la Fiesta de Santiago, día de santa Ana.

\section{Acto primero: El acceso de los oficiantes al espacio ritual de intercambios}

Primer movimiento. El primer tránsito es de orden simbólico, cambio de los significantes de la Fiesta, o, mejor dicho, de la jerarquía de los significantes que supone un cambio de la polaridad de género de los espacios y los tiempos. Se pasa del dominio de lo masculino, que estaba regido por san Santiago, a lo femenino, regido por santa Ana. Lo femenino es lo superordinado, y lo masculino, lo subordinado, en relación a la agencia de la fiesta. Es fundamental para el ritual-performance este cambio de sexualidades, ya que serán las mujeres de Machuca las que organizarán y dirigirán las transferencias rituales de la Feria. Santa Ana es la protectora de las mujeres trabajadoras y de las mujeres embarazadas a la hora del parto, todas estas instancias de transacción —el comercio del trabajo y dadora de los significantes del sistema de parentesco- conforman la base significante del sistema de transacciones del ritual-performativo.

investigadores, y Olaya Sanfuentes, como investigadora principal. Como metodología de registro, producto del particular contexto etnológico, la he llamado libre e irresponsablemente etnografía colaborativa y asociativa. La velocidad de los acontecimientos y su densidad en la situación ritual-performativa obligó a que todo el equipo del proyecto colaborara en base a su experiencia almacenada en su memoria - ya que no se podía filmar, grabar o fotografiar- en la reconstrucción del hecho etnológico; les debo a ellos esta posibilidad de reconstrucción prolija de la feria de Machuca. 
Segundo movimiento. La construcción del pase que permite un visado hacia el espacio ritual controlado por los pacos. Este consiste en la confección, por parte de cada participante que quiera ingresar al espacio ritual, de una autoinvitación, un carnet. A esta se le debe escribir el nombre del participante, puede ser cualquier pedazo de papel, no importa el soporte; lo que importa es la escritura que va a desplazar la pertenencia del sujeto persona a la escritura persona. Es interesante y fundante este giro a lo escritural, cambio del soporte del significante y sustancia del mismo — de los cuerpos a la escritura en papel—, ya que valida la posibilidad de ingresar al espacio ritual. Es este permiso un documento escrito, una escritura asociada claramente a la cédula de identidad que otorga el Estado de Chile a todos sus ciudadanos, para que transiten - en el sentido del pasaje de Gennep (2008) — de su estado natural comunitario a uno burocrático estatal.

Tercer movimiento. Los pacos que controlaban férreamente la entrada (la puerta con reja) no permitirán el acceso a nadie que no esté legitimado por su invitación, el carnet. La persona es transferida en su valor de sujeto anónimo a la credencial (en este caso, ficticia, pero válida), lo que le otorga legitimidad y existencia; uno es el papel que lo identifica, primer intercambio del ritual de reciprocidades: yo soy un carnet de identidad, este desplazamiento me permite ingresar al espacio ritual con el visado de la autoridad represiva: los pacos comandados por el fabriquero. Ellos te abren la reja y puedes ingresar. La escritura en papel ha permitido que el sujeto deje de ser una persona ajena y externa a la comunidad y se transforme en un sujeto partícipe de la comunidad del intercambio entre identidades, de la persona aislada al papel escrito que supone un «contrato social» con la sociedad de Machuca, y del sujeto oral libre al sujeto escritural sujeto. 
Acto segundo: Circuitos del campo ritual y el acceso a los valores de cambio

Primer movimiento. El ingreso está rígidamente controlado al igual que la circulación dentro del espacio ritual. Los pacos han trazado con tiza en el suelo del patio de la iglesia caminos estrechos que permiten a las personas circular solo en línea india. Son senderos rectos que se quiebran en ángulos de noventa grados, los que imponen un sentido de orden y rigidez organizacional. Los pacos dejan entrar a las personas en un flujo lento y regular, bajo estricta supervisión de los pases-carnet, de manera que no se produzcan atochamientos. Por estos caminos de tiza blanca circulan los ofertantes con sus pases en las manos.

Segundo movimiento. Después de un recorrido que cubre la mitad del campo ritual se debe construir un segundo texto en otro pedazo de papel: hay que valorar el grado de intercambio que cada participante va a tener en el interjuego comensalístico. Libremente, cada persona escribe en un papel un valor monetario en pesos en relación a lo que va a consumir. Nuevamente, el sujeto de la ritualidad se desliza a un intercambio donde su invitación-pase-carnet es ahora puro valor de cambio, podríamos decir, un billete de banco para el cambio; y escribe en el papel lo que le parece que él vale como sujeto y como intercambiador.

Tercer movimiento. El sendero de tiza lleva a los participantes al centro del campo ritual, donde está la cruz en un pedestal grande, el calvario; lugar de ofrendas y actos de dones sacros, que se ha transformado en un lugar de intercambio profano puro. Las alfareras-cocineras-banqueras, todas ellas mujeres adultas solventes, intercambiarán el billete del demandante por pedazos de cerámica. 


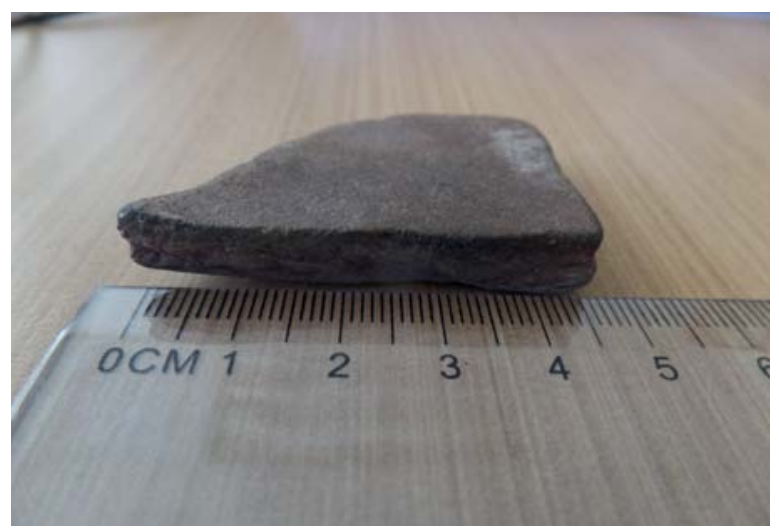

Fotografía 2: fragmento cerámico.

Este intercambio del papel escrito a la cerámica es simbólicamente profundo y de grandes implicancias socioantropológicas. La cifra anotada en el billete guardará correlación con los fragmentos de cerámica que les intercambien las banqueras: un fragmento cerámico equivale a $\$ 1000$ (USD 2). A mayor cifra anotada en el billete, más pedazos de cerámica recibe la persona.

Son fragmentos de cántaros construidos por ellas mismas, cuando eran alfareras (Levi-Strauss 2008: 13-22), alfarería que, al estar rota, alcanza un valor de intercambio. De su producción cerámica ya gastada — diríamos, «hecha pedazos»— se reinstituye en un nuevo valor, canjeables por papel moneda ficticio, por otro valor de cambio dentro de la esfera de lo culinario, la cerámica como posesión única de las mujeres de la comunidad de Machuca. Las alfareras codiciosas anotan prolijamente en un cuaderno los valores de intercambio entre carnet, billetes y cerámica; este procedimiento nos demuestra el control por medio de la escritura que ejercen las mujeres, diríamos que «nada se les escapa», todo queda registrado por el graphos. Así, cada participante recibe proporcionalmente a la cifra que ha escrito en su papel una cantidad de fragmentos de cerámica que le permitirá entrar en el circuito de los intercambios culinarios. 
El espacio está dividido en dos: la entrada y el sendero de tiza hasta el banco, y desde el banco hasta los puestos de comida, que desembocan en un sector amplio del patio sin demarcar, próximo a la salida; el primero está dominado por signos de la textualidad (carnet y billete), el segundo, por los signos de los productos de intercambio femeninos (fragmentos de cerámica por bebidas y comidas).

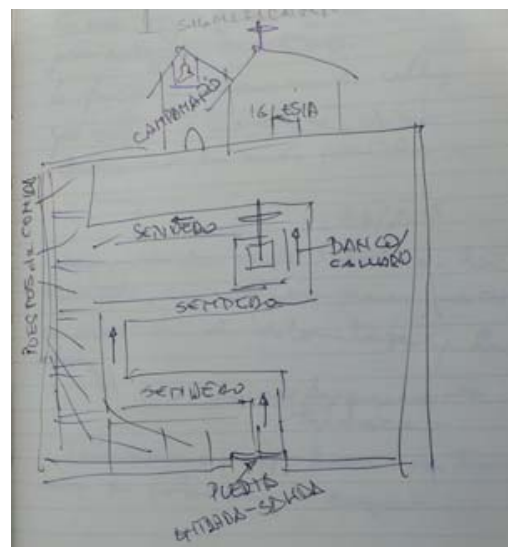

Fotografía 3: bosquejo campo ritual-performativo.

\section{Acto tercero: De la alfarera codiciosa a la alfarera gananciosa}

Primer movimiento. Los participantes deben seguir el sendero de tiza hasta encontrarse con los lugares de intercambio de comida, con sus pedazos de alfarería (puro valor de cambio). Cada lugar está comandado por una mujer adulta y solvente más sus ayudantas menores que, incluso, pueden llegar a ser hombres o niños; cada puesto ofrece diferentes especialidades de comida y bebidas.

Cada participante va intercambiando sus fragmentos de cerámica por lo que quiera, estableciéndose una correlación entre cantidad de ceramios y excelencia de los productos culinarios, esta última está medida por la calidad de los materiales y el trabajo invertido en 
la preparación. Hay una regla más o menos explícita en relación de valores de cambio (fragmentos cerámicos) y productos de la culinaria aimara de Machuca.

Segundo movimiento. El circuito culinario es muy abundante a pesar de la gran cantidad de participantes, la ingesta es copiosa y se va pasando por todo un circuito de puestos siguiendo el sendero de tiza, el que no puede ser trasgredido en sus fronteras, pero ya no hay orden en la elección de los puestos de consumo, orden que queda sujeto a la voluntad del consumidor:

[...] una vez que ya estaban todos adentro, la libre circulación era posible. Uno podía salirse de la línea india para pasar a pedir comida al siguiente puesto (porque uno puede comprar lo que quiera). Lo que estaba estrictamente probibido, y fue por lo que tomaron presa a la Olaya [integrante del equipo de campo], era colarse en la fila de las otras comidas, lo que podría conectarse con el respeto por lo comunitario [relato presencial de Jaime Álvarez].

Claramente, el consumidor puede elegir su dieta a su antojo, pero no trasgredir el tiempo de los demás, que es otro bien de consumo; si se «roba tiempo» de los otros consumidores al infiltrarse en la fila de cada puesto, merece y requiere una sanción.

Los pacos vigilan estrictamente la conducta y opiniones de los comensales. No se pude alegar ni regatear, ni emborracharse, la sanción es inmediata y expulsan al sujeto del circuito de intercambios. Los pacos los reducen al campanario de la iglesia por un tiempo y es liberado previa multa y toque de campana, tres toques. Tampoco se puede fotografiar, el que fotografía se lleva la imagen, nada asegura que retribuya esta acción de sacar imágenes, el hechor debe ser encarcelado y multado. Solo miembros autorizados por la autoridad ritual pueden fotografiar, al parecer, de preferencia, parientes de las alfareras codiciosas. 
Acto cuarto: Hartazgo, fin del circuito comensalístico y el reintegro de excedentes

Primer movimiento. Los participantes han intercambiado valor de cambio, fragmentos de cerámica, por comida y bebida, se llevan en sus cuerpos los resultados del intercambio de las mujeres alfarerascocineras. Han ejecutado la performance de los intercambios de los alimentos y la tierra cocidos, los mediatizados por lo femenino, la alfarería y la cocina. Aquí uno se debe a lo femenino, se ha recibido el don de la tierra mediatizada: primero, la arcilla hecha cerámica, luego, los alimentos hechos comida, y el valor del dinero, del billete de papel, hecho reciprocidad pura.

Segundo movimiento. Terminado el circuito de comidas y bebidas, los participantes deben devolver los pedazos de cerámica que le han sobrado, en esto se es muy estricto. Progresivamente, las alfareras van recuperando su cerámica, su potencial de intercambio, por medio de dos vías. La primera, por medio de la venta de comidas y bebidas, la más importante, la segunda, por medio de los excedentes del consumo en valor cambio, fragmentos cerámicos que no se intercambiaron por parte de los participantes de la feria. Doble circuito que asegura la eterna prosperidad de las alfareras codiciosas.

Tercer movimiento. $\mathrm{Al}$ atardecer, todos los ofertantes han salido del campo ritual, del campo de la feria femenina de la reciprocidad, y deben abandonar el espacio ritual completamente. Las alfareras almacenan y vuelven a atesorar los fragmentos cerámicos en el campanario, en un lugar oculto y recóndito, acción realizada por los pacos. La divinidad los protegerá hasta una nueva feria, es un acto de codicia y poder social, proteger la riqueza de la femineidad en el dominio sagrado, ¿será la codicia algo herética?

Se ha cerrado el espacio ritual performativo a la profanidad de la abundancia y codicia femenina, se borrarán todos los indicios de 
la feria del intercambio entre las personas para reinaugurar de nuevo el espacio de lo sagrado, de los intercambios entre las personas y Dios, dentro de los límites de la iglesia y sus murallas.

\section{Acto final, el terminus: La clausura del espacio profano y la reinstauración del espacio sagrado y la restitución de los do- nes divinos}

Los oficiantes han limpiado el espacio ritual de los vestigios de la profanidad de los intercambios feriales, reúnen leña para las fogatas nocturnas que arderán en los cuatro costados del patio de la iglesia, se han vuelto a abrir las puertas de esta, en una señal de la inauguración de los significantes sacros, la santidad vuelve a estar expuesta a las ofrendas; se la mantuvo clausurada al comercio de las alfareras codiciosas. Ahora solo se podrá entrar a la ceremonia con un objeto de ofrenda: leña, pero ya no para las alfareras codiciosas y sus prácticas de intercambio como signos de la abundancia, sino para la santidad protectora. San Santiago Apóstol ha recuperado su dominio en el marco del espacio sagrado de la iglesia, el calvario y el patio. El santo volverá a regir los dones en un espacio masculino de restitución de lo sagrado (véase esquema 1).

\section{Significados de las REDEFINICIONES, DE LAS ORALIDAdES A LA TEXTUALIDAD. La ORALIDAD RELEgada, LA TEXTUALIDAD INS- TAURADA Y LA MATERIALIDAD EDIFICADA}

Antes de nuestra escritura grafemática y fonética, el ritual debe haber fluido en una performance de la oralidad y la materialidad: palabras y cosas. En algún momento — quizás no muy próximodebe haber irrumpido la fuerza y dominación del texto poderoso: las Escrituras Bíblicas y la Burocracia Estatal. Es característico de ciertos contextos rituales en nuevas situaciones de modernidad que 
sus performances orales se desplacen a textualidades, es lo que técnicamente se denomina entextualización. La base de la entextualización es la replicación, que es el intento por reproducir el discurso; discurso que es irrepetible, dadas sus propiedades formales, «por la infinitamente rica especificidad del contexto en el cual se incrusta, por definición, el discurso no puede ser reproducido. La replicación, de todas maneras, es un contexto de reproducción, al relocalizar la instancia original del discurso en un nuevo contexto, llevando algo desde lo temprano hacia lo tardío» (Urban 1996: 21). Una de las formas de la replicación es la entextualización, si «entextualización es entendida como un proceso de traspasar una instancia dada de discurso a texto, apartándolo de su contexto singular» (Urban 1996: 21). ${ }^{13}$

En el dominio que nos interesa, es muy posible que anteriormente hubiese existido un estricto protocolo oral de acceso al ritual, con una serie de fórmulas encriptadas que dieran la clave de entrada a la Feria, donde unos discursos-enunciados sometían al sujeto a una identificación grupal y le permitían participar de los intercambios. En este caso de ritual-performance hablamos de que entextualización «es el proceso de transformar el discurso en texto [...], en objetos textuales para performances rituales que frecuentemente ocurren en forma de patrones regulares» (Tomlinson 2008: 2 [la cursiva es nuestra]). Sorprende la importancia de la escritura en el patrón performativo del ritual: los carnets que se hacen los participantes son ficticios, no creemos que sean falsos (no hay una intención de engaño, muy por el contrario), de ahí que elijamos la expresión de «ficticio»; los billetes también son ficticios, pero están escritos y eso les basta para su completa legitimidad, todo queda archivado en el cuaderno de contabilidad de las alfareras. Solo al ser intercambiados por fragmentos cerámicos pasan a la cosa, a la cosa con valor, a un valor que no está enajenado por la escritura. Los fragmentos cerá-

13 No tenemos espacio, ni es tampoco el sentido de este artículo tratar con más profundidad el proceso de transferencia, de la oralidad a la textualidad, tan estudiado por la llamada antropología de la textualidad (Barton y Papen 2011). 
micos cabrían en lo que Maurice Godelier llama «cuasimonedas» (1998: 157), los que además «nunca circulan [...] como una mercancía, sino que como un objeto de don» (Godelier 1998: 199). Estos son conservados indefinidamente para la siguiente performance, los papeles escritos se desechan apenas son utilizados, no así el cuaderno, que registra el paso del texto a la cosa cerámica, ese sí se guarda con todos los fragmentos; el intercambio queda historiado en sus volúmenes y participantes.

Unos textos — carnet y billetes - y unas cosas — cerámicas y comidas - no pueden operar en el patrón performativo los unos sin los otros. Inversamente a la sobremodernidad (Augé 2014), la cosa pervive y el signo textual desaparece. ${ }^{14}$ Se ha descubierto el factor normativo y regulador en vinculación al estado y a la escritura (Goody 1990), son los pacos y las banqueras-contadoras que controlan y legitiman la validez de la escritura, que sigue siendo ficticia (no falsa, como dijimos, porque en el ámbito de la performance solo existe la realización de lo ficticio) a diferencia de todo lo demás: personas, espacio-tiempos, fragmentos cerámicos y comidas, que son cosas.

Mecanismo organizativo y represivo de la performance. El espacio ritual, sus tiempos y personas son organizados por las mujeres, ellas son las encargadas de establecer y controlar todo el circuito de intercambios. No es por falta de autoridad que no ejercen la labor de pacos, sino porque ellas se preocupan de organizar los intercambios, no de reprimir y sancionar a los trasgresores. Los invitados se ubican en la periferia del espacio ritual, la entrada, al margen de los senderos de tiza, en la torre de la iglesia, que ha pasado de su función numénica a una profana muy notoria, la de cárcel, o lugar de reclusión. Esto es muy importante en el plano semiótico porque,

14 Marc Augé (2014: 59) entiende la sobremodernidad «como la combinación de tres fenómenos: el estrechamiento del espacio, la aceleración del tiempo y la individualización de los destinos». 
para el mismo significante, la función es, podríamos decir, inversa: de un lugar de conexión semiótico —el campanario, lugar de comunicación entre las personas, la comunidad ritual y la divinidad por el sonido de su campana - a un lugar de incomunicación, la persona alejada de la comunidad, sin poder comunicarse. Solo cuando es liberada por sus captores restablece la comunicación de una manera notoria: toques de campana, así puede volver a comunicarse con la comunidad y lo que aquí es más importante: anunciar su reencuentro con el intercambio de valores.

La factura de los significantes del intercambio. Lo ficticio lo crean los participantes, carnet y papel moneda-billete; lo concreto lo hacen las mujeres oficiantes, la cerámica y la comida, además son las encargadas de traspasar lo ficticio, papel moneda, a lo concreto, fragmentos de cerámica. Son las que rigen el valor y, por extensión, el valor de cambio. La cerámica viene de la tierra, la comida también, son la expresión de lo telúrico fecundo, y también de la reproducción de la sociedad. Todo lo anterior es un juego de intercambio de lo vivo, en las materialidades, de la arcilla a la cerámica, del útero al parentesco, de la comida al estómago. Son ellas la que en su performance explicitan su condición de grandes traspasadoras, de ser el motor articulador de los intercambios de la comunidad de Machuca y de la comunidad con el exterior, los foráneos (véase esquema 2).

\section{Estructura culinaria y proceso de intercambios alimentarios.}

Referiremos brevemente al sistema culinario de la feria de Machuca, nos remitiremos, asumidas las consabidas soluciones estructurales clásicas del Triángulo Culinario, de Claude Lévi-Strauss (1968), a las aportaciones posteriores en este sentido de Adrianne Lehrer, aplicando análisis componencial y campo léxico en diferentes contextos culturales en relación a la operativa «práctica» de la cocina en su Tetraedro Culinario (1972), y, por último, a la síntesis que nos entrega Jack Goody (1995), agregando factores sociológicos de control sobre las comidas y modos de consumo. 
Todas las teorizaciones anteriores permiten hacernos un esquema categorial básico e inicial de las comidas y los consumos en la feria de Machuca. Como categorías complementarias al Triángulo y al Tetraedro, agregamos lo frío y lo caliente, que son indispensables en un circuito del consumo comensalístico, ya que en el consumo se van alternando y son, por lo general, complementarias (véase esquema 3).

Las bebidas alcohólicas son evidentemente podridas, es decir, son sometidas a un proceso de fermentación, su ambigüedad reside en su efecto sobre las personas, aunque se puedan ingerir frías, calientan el cuerpo; a esta ambigüedad en su temperatura se le agrega que las conductas y los dichos de las personas consumidoras son impredecibles. La bebida alcohólica sumaría este doble factor de ambigüedad en su constitución e impredecible en sus efectos sobre las personas (véase esquema 4).

Lo importante a destacar es que se trata de una exococina, «la que se ofrece a los invitados» (Lévi-Strauss 1968: 44), aunque muchas de las comidas provienen de una endococina, son expuestas en la feria fuera de los confines de la familia, inclusive de la comunidad, al compartirla con invitados y curiosos, lo que refuerza el sentido de espacio abierto de toda feria en oposición al espacio ritual sagrado de la fiesta.

Evidentemente, la complejidad de la oferta culinaria tiene que ver con el esfuerzo comensalístico, ya que «el comensalismo fue considerado el gran promotor de la solidaridad, de la comunidad: la comunidad de hermanos refuerza los lazos comunes» (Goody 1995: 25).

\section{Transferencias y temperamentos EN EL DOMinio de LA AL- FARERA CODICIOSA}

[...] creencias antiguas y generalizadas según las cuales hay una homología entre dos sistemas: el de las ocupaciones profesionales y el de los temperamentos (Lévi-Strauss 2008: 5). 
La feria de Machuca se nos instituye como un dominio de lo femenino en sus símbolos y agendas, no es que se excluya a los hombres, sino que se los relega a la función de controladores de las prácticas estando bajo el dominio del capital, como toda policía; las alfareras pagan a su policía con bebidas alcohólicas, cerveza y pisco principalmente, siempre el capital ha emborrachado a sus policías para que sean brutalmente efectivos.

La fiesta devela los tránsitos que constituyen la praxis de las alfareras codiciosas, la acumulación y posterior distribución de bienes en un tejido social, de reciprocidad. Este ejercicio supone un vasto procedimiento de transacciones y mediaciones de capital objetual y simbólico que ellas monopolizan.

La alfarera media su actividad por medio del agua y fuego al someter a la arcilla al modelado y posterior cocción. Roto el ceramio por su uso, ocupan los fragmentos como valor de intercambio, los acumulan y utilizan a los pacos para que los atesoren en el campanario. No desechan los fragmentos, sino que los reutilizan, claro significante de su avaricia, nada se bota. Todo se intercambia. Inicialmente, median el valor escrito en papel como billete por fragmentos de cerámica. Por último, median entre los fragmentos y la comida y la bebida para afianzar su red de relaciones interpersonales por medio del don comensalístico.

Si la fiesta es clausurada, o mucho más restrictiva en sus protocolos de inclusión, la feria ${ }^{15}$ (ya su denominación la delata, en América las ferias son públicas, son el gran lugar de los encuentros por medio de los intercambios) es mucho más abierta e inclusiva, se trata de intercambiar, de comerciar, de hablar, de conocerse y, como decía en alguna parte un personaje muy codicioso de Isaac Bashevis Singer, que los comerciantes, por último, son los encargados de vincular a las personas desconocidas.

15 Feria, su etimología viene del griego: pher, 'llevar'; todos acarrean algo a la feria, desde sus productos, su hambre, su palabra o su curiosidad, es un espacio asequible por definición. 


\section{El VAlOR RESTITUIDo}

Nuestras sociedades han canalizado el don. Lo han encajado en el valor de cambio y los procedimientos económicos. Nuestras sociedades, es decir, el tipo de estructura que aparece poco a poco pero con una fuerza creciente, cuando los hombres han descubierto y experimentado la fuerza de la acumulación y de la redituabilidad. Mas, ¿'estamos confinados definitivamente en estas sociedades? (Duvignaud 1979: 156-157).

¿Qué revela la feria de Machuca? Da la impresión de que es un esfuerzo por redefinir los valores de cambio, de la enajenación del papel escrito transformado en valor abstracto y absoluto, a su cosificación desenajenada en fragmentos de cerámica. Las alfareras codiciosas nos quieren demostrar cómo intercambiar y qué intercambiar en un contexto de modernidad cuyo signo es la escritura. El papel moneda y los fragmentos de cerámica nos advierten que no hay que engañarse entre las relaciones de intercambio y las de reciprocidad.

Es como si ellas nos dijeran que solo se puede establecer relaciones de reciprocidad por medio de un bien, no de una abstracción; hay que cambiar lo escrito por lo modelado. Solo el objeto de la alfarería tiene valor de don, solo con ese valor se puede uno sumergir en la red de intercambios comensalísticos. Lo escrito habilita al intercambio, pero no lo permite; también con este uno puede acceder al espacio ritual performativo de la feria y acceder al intercambio de fragmentos cerámicos, nada más; el intercambio solo es posible por un bien y producto que es exclusivo de las mujeres de Machuca. Los habitantes de Machuca han logrado una síntesis entre lo moderno (el complejo de la escritura) y lo propiamente constitutivo de su sistema de intercambios (complejo femenino productivo de bienes propios: cerámicos).

Es una suerte de advertencia, debemos introducirnos en el dominio de lo escrito por un tránsito de la externalidad al interior del circuito de intercambios, pero el núcleo de transacciones e intercambios de fragmentos cerámicos por comida se deben realizar, 
nos dice la comunidad, con nuestros valores: el producto de nuestro trabajo primordial, y con nuestros elementos constitutivos de nuestro mundo: arcilla, agua, aire y fuego. Que son los de la industria de las alfareras.

Las alfareras cocineras codiciosas fijan en sus términos mixtos — escritura y alfarería — las reglas del comensalismo, la cualidad del valor de cambio, y te alimentan o te proscriben.

Nada se pierde, todo circula, los bienes y las personas y sus símbolos, podemos decir que todo se consume, salvo la reutilización indefinida de los fragmentos cerámicos para futuras ferias, que son el significante de todas las circulaciones. Machuca refuerza su unidad en la mujer, como en los sistemas de parentesco, ${ }^{16}$ basados en el intercambio y la reproducción por alianzas. La feria es un sistema abierto, permite que la visita y los intrusos eventuales participen, la alfarera no es solo codiciosa con su cuasimoneda-cerámica, sino también con todas las personas, a todos y todas las quiere capturar en su red de reciprocidades al saberse poseedora de un instrumento económico político poderoso, ya que «tanto negarse a dar como de olvidarse de invitar o negarse a aceptar, equivale a declarar la guerra, pues es negar la alianza y la comunión» (Mauss 1971: 169-170). Así, dando, las mujeres adultas de Machuca obligan a ser parte de sus vínculos.

16 Véase las ideas de Levi-Strauss (1969: 91-106) sobre el principio de reciprocidad. También Fox (1985). 


\section{ESQUEMAS}

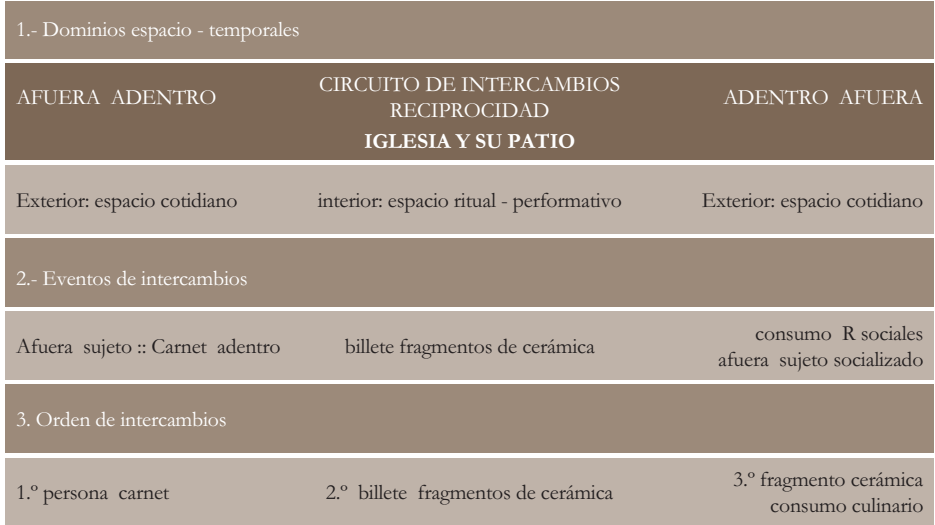

\section{MUJER - CODICIA \\ TIERRA - ARCILLA \\ PRIMERA MEDIACIÓN ALFARERA \\ TRABAJO ARCILLA}

(Agua/fuego/aire)

actividad alfarera

\section{CERÁMICA}

\section{SEGUNDA MEDIACIÓN COCINERA ALFARERÍA ALIMENTOS}

(Agua/fuego/aire)

Preparación de comida

COMIDA

\section{TERCERA MEDIACIÓN MERCADORA BILLETES FRAGMENTOS CERÁMICOS}

(Escritura/fragmentos cerámicos)

Ingestión de alimentos

RECIPROCIDAD TOTAL 


\section{SITUACIÓN DE CONSUMO}

\section{FRÍO // CALIENTE}

Frito: (Berlín, sopaipilla, papas fritas) COMIDA Cocido - hervido: (cazuela, pataska) Crudo: (bebidas gaseosas, agua) BEBIDAS Cocido: (chocolate caliente) Podrido: (bebidas alcohólicas)

\begin{tabular}{|c|c|}
\hline \multicolumn{2}{|c|}{ ALIMENTOS } \\
\hline COMIDAS & BEBIDAS \\
\hline Frito / Cocido - Hervido & Crudo/Podrido \\
\hline $\begin{array}{c}\text { Berlín: Sopaipilla: papas fritas } \\
\text { / Cazuela: pataska }\end{array}$ & Bebidas: gaseosas, agua \\
\hline
\end{tabular}

\section{REFERENCIAS}

Augé, Marc

2014 Cinco conferencias sobre antropología y globalización: Las conferencias del sur. Valparaíso: Ediciones Universitarias de Valparaíso.

Barton, D. y Uta Papen

2011 The Anthropology of Writing. London: Continuum International Publishing.

BLACK, Max

1962 Models and Metaphors. Ithaca: Cornell University Press.

Cazeneuve, Jean

1972 Sociología del rito. Buenos Aires: Amorrortu Editores.

Duvignaud, Jean

1979 El sacrificio inútil. México: Fondo de Cultura Económica.

Fox, Robin

1985 Kinship \& Marriage. New York: Viking Penguin. 
Genner, Arnold van

2008 Los ritos de paso. Madrid: Alianza Editorial.

GODELIER, Maurice

1998 El enigma del don. Barcelona: Paidós.

Goody, Jack

1990 La lógica de la escritura y la organización social. Madrid: Editorial Alianza.

1995 Cocina, cuisine y clase: Estudios de sociología comparada. Barcelona: Gedisa.

Hawley, Amos H.

1975 Ecología humana. Madrid: Editorial Tecnos.

Kessel, Juan van

1996 «Los aymaras contemporáneos de Chile». En: Jorge Hidalgo, Virgilio Schiappacasse, Hans Niemeyer, Carlos Aldunate y Pedro Mege (eds.). Etnografía: Sociedades indígenas contemporáneas y su ideología. Santiago de Chile: Editorial Andrés Bello, pp. 47-68.

LEHrER, Adrianne

1972 «Cooking vocabularies and the Culinary Triangle of Lévi-Strauss». Anthropological Linguistics, n. 14, pp. 155-171.

LÉvi-STrauss, Claude

1968 Estructuralismo y dialéctica. Barcelona: Paidós.

1969 Las estructuras elementales del parentesco. Buenos Aires: Paidós.

2008 La alfarera celosa. Barcelona: Paidós.

Mauss, Marcel

1971 Sociología y antropología. Madrid: Editorial Tecnos.

SCHECHNER, Richard

1995 The future of Ritual. Writings on culture and performance. New York: Routledge.

2000 Performance. Teoría y práctica. Buenos Aires: Editorial Universidad de Buenos Aires. 
TAYLOR, Diana y Marcela Fuentes

2011 Estudios avanzados de performance. México: Fondo de Cultura Económica.

Tomlinson, Matt

2008 Ritual Textuality. New York: Oxford University Press.

TURNER, Victor

1975 Drama, Fields and Metaphors. Ithaca: Cornell University Press.

1982 The ritual Procees: Structure and Anti-Structure. Ithaca: Cornell University Press.

1988 The Anthropology of Performance. New York: PAJ Publications.

2008 «Symbols in Ndembu Ritual (1967)». En: Paul A. Erickson y Liam D. Murphy (eds.). Reading for a History of Anthropological Theory. 4. ${ }^{\mathrm{a}}$ edición. Toronto: University of Toronto Press, pp. 273-289.

URBAN, Greg

1996 «Entextualization, Replication, and Power». En: Michael Silversatein y Greg Urban (eds.), Natural Histories of Discurse. Chicago: University of Chicago Press, pp. 21-44. 